\title{
Simultaneous removal of nitrate and phosphate from wastewater using solid waste from factory
}

\author{
Yifru Waktole Berkessa ${ }^{1} \cdot$ Seid Tiku Mereta ${ }^{1} \cdot$ Fekadu Fufa Feyisa $^{2}$
}

Received: 27 November 2016 / Accepted: 10 February 2019 / Published online: 22 February 2019

(c) The Author(s) 2019

\begin{abstract}
Phosphorous and nitrogen concentration, respectively, between $20-100$ and 500-1000 $\mu \mathrm{g} / \mathrm{L}$ can cause eutrophication. Thus, developing efficient low-cost removal method is important to protect the aquatic environment. The aim of this study is to investigate simultaneous nitrate and phosphate adsorption capacity of solid waste residue (SWR) generated from Awash Melkassa Aluminium Sulphate and Sulphuric Acid Factory. Batch adsorption experiments were conducted to evaluate the effect of various parameters on the simultaneous removal of nitrate and phosphate ions. The experimental results show that the equilibrium time was attained within $90 \mathrm{~min}$, while the optimum $\mathrm{pH}$ and adsorbent dose were found to be 7 and $20 \mathrm{~g} / \mathrm{L}$, respectively. The pseudo-second-order equation with $R^{2}$ values 0.99 and 1 , respectively, fits to the adsorption kinetics of nitrate and phosphate. Moreover, isotherm analysis shows that adsorption of nitrate and phosphate was better modeled with Freundlich and Langmuir isotherms with $R^{2} 0.99$ and 0.98 for phosphate and 0.99 and 0.96 for nitrate, respectively. Results of regeneration of the spent adsorbent show nearly $50 \%$ of the adsorbed phosphate can be desorbed with $\mathrm{NaOH}$, while that of nitrate is $99.75 \%$. Under optimum conditions, SWR can potentially remove phosphate from wastewater. However, the adsorbent is not suitable to remove nitrate ion from wastewater.
\end{abstract}

Keywords Simultaneous removal $\cdot$ Batch adsorption $\cdot$ Chemisorption $\cdot$ Solid waste

\section{Introduction}

According to the famous Redfield ratio, the molecular ratio of carbon, nitrogen and phosphorus in phytoplankton is $\mathrm{C}: \mathrm{N}: \mathrm{P}=106: 16: 1$ (Liang 2007). Discharge of wastewater containing excess nitrogen and/or phosphorus species is a serious environmental problem worldwide, as these nutrients cause eutrophication of surface water bodies (Khelifi et al. 2002; Painting et al. 2007; Tiemeyer et al. 2009; Wei et al. 2008). Terrestrial ecosystems and headwater streams have a considerable ability to capture nitrogen or to change it to $\mathrm{N}_{2}$ gas through denitrification (Vitousek et al. 2002). However, when loads of nitrogen from sources, such as fertilizer, septic tanks and atmospheric deposition, exceed the capacity

Fekadu Fufa Feyisa

fekaduff2010@gmail.com

1 Department of Environmental Sciences and Technology, College of Health Sciences, Jimma University, Jimma, Oromia, Ethiopia

2 Civil and Environmental Engineering School, Jimma Institute of Technology, Jimma University, Jimma, Oromia, Ethiopia of terrestrial systems, cascading harmful effects could be happened as nitrogen moves downstream to coastal ecosystems (Galloway and Cowling 2002). Likewise, several million tons of phosphorus-containing wastewater is directly discharged into the watercourses in the developing countries causing environmental damage. Hence, eutrophication of aquatic environment frequently causes fish kills, phytoplankton blooms, and deteriorates water quality (Song et al. 2011).

Consequently, nutrient removal from wastewater is imperative to deter eutrophication of water bodies and various techniques, such as chemical precipitation (Huang et al. 2017), adsorption (Fink et al. 2016), reverse osmosis (Luo et al. 2017), biological removal (Chiu et al. 2015), electrodialysis (Guedes et al. 2016) and constructed wetlands (Wu et al. 2015) widely employed to remove nutrients from wastewaters (Zeng et al. 2004). Enhanced biological treatment can remove up to $97 \%$ of the total phosphorus though variability in chemical composition and temperature of wastewater would make the implementation of this process not feasible for wastewater treatment (Zhao et al. 2009). On the other hand, physical methods have been proved to be either too expensive, as in the case of electrodialysis and 
reverse osmosis, or inefficient, removing only $10 \%$ of the total phosphorus (Zhao et al. 2009). Generally, the above methods are high tech and consequently need high cost which makes it difficult to apply in the context of developing countries like Ethiopia. However, adsorption method has become a popular method since it allows simple and economical operation resulting in less sludge production and fewer disposal problems (Olgun et al. 2013). Moreover, nutrient-loaded exhausted adsorption media can be used in agriculture as a phosphate fertilizer and soil conditioner (Zeng et al. 2004). The objective of this study was to explore the feasibility of using residual solid waste (RSW) from manufacturing of aluminum sulfate and sulfuric acid for simultaneous removal of nitrate and phosphate ions from aqueous solution. Moreover, the study addressed optimization, sorption kinetics study, isotherm study and desorption studies explain sorbent-sorbate interaction (s).

\section{Materials and methods}

\section{Solution preparation and measurement of ion concentration}

Stock phosphate solution was prepared by dissolving $0.7165 \mathrm{~g}$ anhydrous $\mathrm{KH}_{2} \mathrm{PO}_{4}(99.5 \%$ pure) in deionized water and diluted to $1000 \mathrm{~mL} ; 1.00 \mathrm{~mL}=500 \mu \mathrm{g} \mathrm{PO}_{4}{ }^{3-}$-P. In the same way, stock nitrate solution was prepared dissolving oven-dried $0.7218 \mathrm{~g} \mathrm{KNO}_{3}(99.5 \%$ pure) pure in $1000 \mathrm{~mL}$ distilled water; $1.00 \mathrm{~mL}=100 \mu \mathrm{g} \mathrm{NO}_{3}{ }^{-}$-N according to standard methods for the examination of water and wastewater (Association APH, Association AWW 1989). Concentrations of nitrate and phosphate in the supernatant solution were analyzed according to standard method for the examination of water and wastewater (Association APH, Association AWW 1989) by ultraviolet screening method for nitrate ions and stannous chloride method for phosphate using UV-Vis spectrophotometer (DR 500) at 220 and $690 \mathrm{~nm}$, respectively. One $\mathrm{mL}$ of $1 \mathrm{~N} \mathrm{HCl}$ was added to $50 \mathrm{~mL}$ of clear supernatant to treat samples prior to reading for nitrate ion concentration, and deionized water was used as a blank during measurement. Moreover, interference due to organic matter was monitored by measuring absorbance of the supernatant solution at $275 \mathrm{~nm}$. On the other hand, the sample for measurement of concentration of phosphate in the supernatant was prepared by first adding phenolphthalein indicator solution and strong acid solution was added till the pink color disappears. Acid-molybdate solution $(4 \mathrm{~mL})$ was added to each of the standards and sample and thoroughly mixed by inverting each flask four to six times. Then, $0.5 \mathrm{~mL}$ (10 drops) of stannous chloride solution was added to each of the standards and sample, and the flasks were stoppered and mixed by inverting each flask four to six times. Finally, after $10 \mathrm{~min}$, but before $12 \mathrm{~min}$, the color was photometrically measured for phosphate concentrate at $690 \mathrm{~nm}$ using distilled water as a blank. Last but not least, average of the duplicate measurements was reported for all data in this work.

\section{Adsorbent}

Samples of SWR were collected from eight batches stocked in the compound of Awash Melkassa Alum and Sulphuric Acid Factory, East Shewa Zone, Oromia Regional State, Ethiopia. The collected samples were mixed in a 1:1 ratio and dried at laboratory room temperature. The dried composite SWR samples were ground using mortar and sieved using sieves of mesh sizes $212 \mu \mathrm{m}$. Particle size less than $212 \mu \mathrm{m}$ was stored in an airtight plastic bottle for further experimental uses. The chemical and mineralogical compositions of the SWR were previously analyzed (Habte et al. 2014).

\section{Adsorption procedures}

Sets of duplicate batch adsorption experiment were conducted at room temperature. A solution of known concentrations of phosphate and nitrate was contacted with desired amount of SWR for a predetermined contact time under room temperature with blank and control experiments. Equilibrium time was determined by varying the contact time from 0 to $120 \mathrm{~min}$ and allowing $100 \mathrm{~mL}$ test solution containing $19.3 \mathrm{mg} / \mathrm{L}$ orthophosphate and $5.14 \mathrm{mg} / \mathrm{L} \mathrm{NO}_{3}-\mathrm{N}$ to be adsorbed onto $20 \mathrm{~g} \mathrm{SWR}$ dose via shaking the mixture in the $250-\mathrm{mL}$ plastic bottle at $150 \mathrm{rpm}$. Optimum $\mathrm{pH}$ for maximum simultaneous removal of nitrate and phosphate ions was determined in a solution $\mathrm{pH}$ range of 2-12 allowing $20 \mathrm{mg} / \mathrm{L}$ SWR to adsorb $19.3 \mathrm{mg} / \mathrm{L}$ orthophosphate and $5.14 \mathrm{mg} \mathrm{NO}{ }_{3}-\mathrm{N} / \mathrm{L}$ in $250-\mathrm{mL}$ container, respectively. The effect of adsorbent dose was investigated by varying the dose of SWR from 4 to $32 \mathrm{~g} / \mathrm{L}$ at solution $\mathrm{pH} 7$ and $150 \mathrm{rpm}$. Moreover, effect of the initial nitrate and phosphate concentrations on the simultaneous removal efficiency varying nitrate and phosphate concentrations from 3 to $19 \mathrm{mg} / \mathrm{L}$ and 0.2 to $260 \mathrm{mg} / \mathrm{L}$ was studied, respectively. Furthermore, the effect of three coexisting ions such as chloride, bicarbonate and sulfate on simultaneous removal of nitrate and phosphate was studied by varying the concentration of each of the interfering ions from 5 to $100 \mathrm{mg} / \mathrm{L}$.

\section{Desorption experiment}

Known concentration of phosphate $(19.3 \mathrm{mg} / \mathrm{L}$ orthophosphate) and nitrate $\left(5.14 \mathrm{mg} \mathrm{NO}_{3}-\mathrm{N} / \mathrm{L}\right)$ was allowed to be adsorbed onto $20 \mathrm{~g}$ SWR at equilibrium time. Then, the supernatant was analyzed for residual adsorbate after 
separating the adsorbent by filtration preceded by centrifugation. The spent adsorbent separated through filtration was dried for $24 \mathrm{~h}$ at $105{ }^{\circ} \mathrm{C}$. The oven-dried exhausted SWR was agitated varying concentration of $\mathrm{NaOH}(0.1,0.5$ and $1.0 \mathrm{M})$ separately. Finally, the supernatant and adsorbent were separated by filtration using filter paper to analyze the amount of phosphate and nitrate desorbed.

\section{Adsorption kinetics}

The amount of adsorbate adsorbed at any time, $t$, onto the solid wastes is computed according to Eq. (1):

$q_{\mathrm{t}}=\frac{\left(C_{0}-C_{\mathrm{t}}\right) * V}{M}$

where $C_{0}(\mathrm{mg} / \mathrm{L})$ and $C_{\mathrm{e}}(\mathrm{mg} / \mathrm{L})$ are sorbate (nitrate and phosphate) concentrations at time 0 and $t$, respectively. $V$ is the volume of the solution (L) and $M$ is the mass of alum waste $(\mathrm{g})$. Percentage removal of anions was calculated by the following formula:

$A(\%)=\frac{\left(C_{0}-C_{\mathrm{t}}\right)}{C_{0}} * 100$

where $C_{0}(\mathrm{mg} / \mathrm{L})$ and $C_{\mathrm{t}}(\mathrm{mg} / \mathrm{L})$ are initial and final concentrations of sorbate (nitrate and phosphate) at time 0 and $t$, respectively. Moreover, adsorption kinetics is one of the important characteristics defining the efficiency of adsorbent media. Accordingly, the kinetics of simultaneous nitrate and phosphate adsorption was evaluated applying pseudo-firstorder and pseudo-second-order models.

\section{Pseudo-first-order kinetics}

Lagergren presented a first-order rate equation to describe the kinetic process of liquid-solid phase adsorption (Lagergren 1898), which is expressed as given in Eq. (3):

$\frac{\mathrm{d} q_{\mathrm{t}}}{\mathrm{d}_{\mathrm{t}}}=k_{1}\left(q_{\mathrm{e}}-q_{\mathrm{t}}\right)$

where $q_{\mathrm{e}}(\mathrm{mg} / \mathrm{g})$ and $q_{\mathrm{t}}(\mathrm{mg} / \mathrm{g})$ are the amounts of nitrate and phosphate adsorbed on the adsorbent at equilibrium and at any time $t$, respectively, and $k_{1}\left(\mathrm{~min}^{-1}\right)$ is the rate constant of the first-order adsorption. After integration and applying boundary conditions $q_{\mathrm{t}}=0$ at $t=0$ and $q_{\mathrm{t}}=q_{\mathrm{t}}$ at time $=t$, the integrated form of Eq. (3) becomes:

$\ln \left(q_{\mathrm{e}}-q_{\mathrm{t}}\right)=\ln q_{\mathrm{e}}-k_{1} t$

The value of $k_{1}$ and $q_{\mathrm{e}}$ can be obtained from the slope and intercept of the linear plot of $\ln \left(q_{\mathrm{e}}-q_{\mathrm{t}}\right)$ versus $t$, respectively.

\section{Pseudo-second-order kinetics}

The pseudo-second-order kinetic model presented by Ho and McKay (1999) is given in Eq. (5):

$\frac{\mathrm{d} q_{\mathrm{t}}}{\mathrm{d}_{\mathrm{t}}}=k_{2}\left(q_{\mathrm{e}}-q_{\mathrm{t}}\right)^{2}$

where $k_{2}(\mathrm{~g} / \mathrm{mg} \mathrm{min})$ is the rate constant of the second-order equation; $q_{\mathrm{e}}(\mathrm{mg} / \mathrm{g})$ is the maximum adsorption capacity; and $q_{\mathrm{t}}(\mathrm{mg} / \mathrm{g})$ is the amount of adsorbate adsorbed at time $t$ (min). After integrating Eq. (5) by applying the conditions $q_{\mathrm{t}}=0$ at $t=0$ and $q_{\mathrm{t}}=q_{\mathrm{t}}$ at $t=t$, Eq. (5) becomes:

$\frac{t}{q_{\mathrm{t}}}=\frac{1}{k_{2}} \frac{\mathrm{q}_{\mathrm{e}}}{q_{\mathrm{t}}}+\frac{t}{q_{\mathrm{e}}}$

The value of $q_{\mathrm{e}}$ and $k_{2}$ can be obtained from the slope and intercept of the linear plot of $t / q_{\mathrm{t}}$ versus $t$, respectively. The value of $q_{\mathrm{e}}$ and $k_{2}$ can be obtained from the slope and intercept of the linear plot of $t / q_{\mathrm{t}}$ versus $t$, respectively.

\section{Intraparticle diffusion model}

Intraparticle diffusion model based on the theory proposed by Weber and Morris was used to determine whether particle diffusion was rate-limiting step or not during adsorption of nitrate and phosphate onto SWR. The mathematical equation for intraparticle diffusion model is given in Eq. (7) (Weber and Morris 1963):

$q_{\mathrm{t}}=k_{\mathrm{p}} t^{0.5}$

where $q_{\mathrm{t}}$ is the amount of phosphate or nitrate adsorbed $(\mathrm{mg} / \mathrm{g})$ at a given time $t(\mathrm{~min})$ and $k_{\mathrm{p}}\left(\mathrm{mg} / \mathrm{g} \mathrm{min}{ }^{1 / 2}\right)$ is the intraparticle diffusion rate constant. The $k_{\mathrm{p}}$ value was obtained from plotting of $q_{\mathrm{t}}$ versus $t^{0.5}$.

\section{Adsorption isotherm}

Adsorption isotherm is a curve describing the phenomenon governing the retention (release) or mobility of a substance from the aqueous porous media or aquatic environments to a solid phase at a constant temperature and $\mathrm{pH}$ (Boparai et al. 2011; Foo and Hameed 2010; Kebede et al. 2016). Accordingly, the relationship between the amount adsorbed and adsorbate concentrations (nitrate and phosphate) in the aqueous phase at equilibrium was evaluated using three isotherm models: Langmuir, Freundlich and Dubinin-Radushkevich (D-R) models.

\section{Langmuir isotherm}

Langmuir isotherm model which was originally used to describe gas sorption on monolayer homogeneous solid 
surface with an assumption of identical adsorption sites could be used to predict adsorbate-adsorbent interaction at liquid-solid interface (Langmuir 1918). The Langmuir equation is summarized as in (Eq. 8):

$q_{\mathrm{e}}=\frac{q_{\max } K_{\mathrm{L}} C_{\mathrm{e}}}{1+K_{\mathrm{L}} C_{\mathrm{e}}}$

where $q_{\mathrm{e}}$ is the amount adsorbed $(\mathrm{mg} / \mathrm{g}), C_{\mathrm{e}}$ is the equilibrium concentration of adsorbate $(\mathrm{mg} / \mathrm{L})$, while $q_{\max }$ and $K_{\mathrm{L}}$ are constants related to adsorption capacity and energy of adsorption, respectively (Zeng et al. 2004). Moreover, a dimensionless constant, commonly known as separation factor $\left(R_{\mathrm{L}}\right)$ defined by Webber and Chakkravorti, is presented in Eq. (9):

$R_{\mathrm{L}}=\frac{1}{1+K_{\mathrm{L}} C_{0}}$

where $K_{\mathrm{L}}(\mathrm{L} / \mathrm{mg})$ refers to the Langmuir constant and $C_{0}$ is the adsorbate initial concentration $(\mathrm{mg} / \mathrm{L})$. The computed $R_{\mathrm{L}}$ value suggests the adsorption nature to be either unfavorable $\left(R_{\mathrm{L}}>1\right)$, linear $\left(R_{\mathrm{L}}=1\right)$, favorable $\left(0<R_{\mathrm{L}}<1\right)$ or irreversible $\left(R_{\mathrm{L}}=0\right)$ (Foo and Hameed 2010).

\section{Freundlich isotherm}

The Freundlich isotherm is used to describe non-ideal sorption on heterogeneous surfaces and multilayer sorption; Freundlich isotherm is summarized according to equation (Zeng et al. 2004).

$q_{\mathrm{e}}=k_{\mathrm{f}} C_{\mathrm{e}}^{1 / n}$

where $C_{\mathrm{e}}$ is the equilibrium concentration $(\mathrm{mg} / \mathrm{L})$ and $k_{\mathrm{f}}$ and $n$ are Freundlich isotherm constants related to adsorption capacity and adsorption intensity, respectively.

\section{Dubinin-Radushkevich isotherm}

Another equation used during analysis was the D-R model which is written as (Fekadu 2016; Kooh et al. 2017):

$q_{\mathrm{e}}=q_{\mathrm{m}} \exp \left(-\beta \varepsilon^{2}\right)$

where $q_{\mathrm{m}}$ is the $\mathrm{D}-\mathrm{R}$ constant. The sorption data were modeled by $\mathrm{D}-\mathrm{R}$ isotherm to determine the adsorption type as physisorption or chemisorption. The linear form of D-R model is expressed by the following equation.

$\ln q_{\mathrm{e}}=\ln q_{\mathrm{m}}-\beta \varepsilon^{2}$

where $q_{\mathrm{e}}$ is the amount of nitrate or phosphate adsorbed per unit dosage of the adsorbent $(\mathrm{mol} / \mathrm{g}), q_{\mathrm{m}}$ is the monolayer capacity $(\mathrm{mol} / \mathrm{g}), C_{\mathrm{e}}$ is the equilibrium concentration of nitrate or phosphate $(\mathrm{mol} / \mathrm{L}), \beta$ is the activity coefficient related to mean sorption energy $\left(\mathrm{mol}^{2} / \mathrm{kJ}^{2}\right)$ and $\varepsilon$ is the Polanyi potential described as:

$\varepsilon=R T \ln \left(1+\frac{1}{C_{\mathrm{e}}}\right)$

The mean sorption energy, $E(\mathrm{~kJ} / \mathrm{mol})$, can be calculated as:

$E=\frac{1}{\sqrt{-2 \beta}}$

\section{Relative fitting error parameter}

The best-fit model was determined by evaluating the relative fitting error parameter (RFEP) value which was computed using Eq. (15) (Han et al. 2012):

$\operatorname{REEP}=\sqrt{\frac{\operatorname{SSR} /(n-2)}{q_{\text {ave }}}}$

where $q_{\text {ave }}$ is the average value of the amount adsorbed per mass of adsorbent, $n$ is the number of data points and SSR is the squared sum of residuals. The small values of RFEP represent better capability of the models to fit the experimental data.

\section{Results and discussions}

\section{Effect of contact time}

Equilibrium time was determined by varying the contact time from 0 to $120 \mathrm{~min}$ and allowing $100 \mathrm{~mL}$ test solution containing $19.3 \mathrm{mg} / \mathrm{L}$ orthophosphate and $5.14 \mathrm{mg} / \mathrm{L} \mathrm{NO}_{3}-\mathrm{N}$ to be adsorbed onto $20 \mathrm{~g}$ SWR dose via shaking the mixture in the $250-\mathrm{mL}$ plastic bottle at $150 \mathrm{rpm}$. The results show that removal of nitrate increased with time and reached maximum $\left(0.071 \mathrm{NO}_{3}-\mathrm{N} \mathrm{mg} / \mathrm{g}\right)$ at $60 \mathrm{~min}$ and became stable afterward (Fig. 1). Previous researchers reported similar finding, and the result is in agreement with the removal of nitrate using modified rice husk (Katal et al. 2012). Likewise, the amount of phosphate adsorbed was $0.962 \mathrm{mg} / \mathrm{g}$ in the first $60 \mathrm{~min}$ and almost remained unchanged afterward. Consequently, $90 \mathrm{~min}$ was considered as equilibrium time, and this result agrees with the previous report (Baraka et al. 2012; Kamiyango et al. 2009).

\section{Adsorption kinetics}

Adsorption kinetics of simultaneous removal of nitrate and phosphate was evaluated by applying the pseudo-first- and pseudo-second-order kinetics equation. The parameters of the pseudo-first- and pseudo-second-order equations 


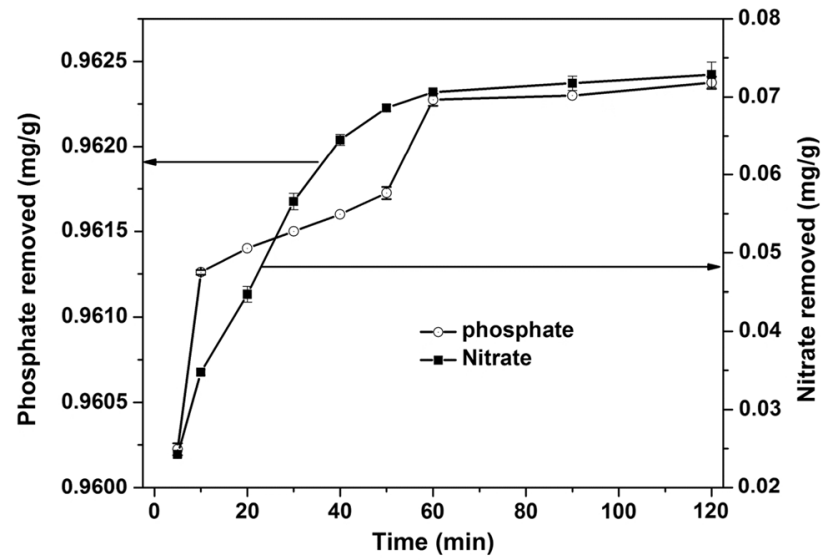

Fig. 1 Effects of contact time on simultaneous removal of nitrate and phosphate ions

for phosphate and nitrate adsorption on SWR are given in Table 1. The kinetic data well fitted to pseudo-second-order kinetics with $R^{2} 1$ and 0.992 (Table 1) for phosphate and nitrate, respectively. Similarly, $R^{2}$ value for the pseudo-firstorder kinetics of phosphate was 0.915 , while that of nitrate was 0.698 . This shows that the phosphate and nitrate adsorption kinetics data were better described by pseudo-secondorder kinetics than pseudo-first-order kinetics. The fact that the kinetic data of both phosphate and nitrate better fitted to pseudo-second-order kinetics shows that chemisorption was the dominant rate controlling mechanism during mass transfer between sorbate and sorbent. Furthermore, the higher $q_{\mathrm{e}}$-experimental compared to $q_{\mathrm{e}}$-calculated during adsorption of nitrate and $q_{\mathrm{e}}$-experimental as high as $q_{\mathrm{e}}$-calculated during adsorption of phosphate suggests chemisorption is that dominant mechanism.

\section{Effect of solution $\mathrm{pH}$}

Figure 2 shows that high phosphate removal efficiency was observed between $\mathrm{pH} 5$ and 9, whereas high nitrate removal

Table 1 Parameters of pseudo-first- and pseudo-second-order adsorption kinetics of phosphate and nitrate

\begin{tabular}{llllll}
\hline Adsorbate & \multicolumn{2}{l}{ Pseudo-first order } & & \multicolumn{2}{l}{ Pseudo-second order } \\
\cline { 2 - 3 } \cline { 6 - 6 } \cline { 5 - 6 } Parameters & Value & & Parameters & Value \\
\hline \multirow{2}{*}{ Phosphate } & $q_{\mathrm{e}}(\mathrm{mg} / \mathrm{g})$ & 0.962 & & $q_{\mathrm{e}}(\mathrm{mg} / \mathrm{g})$ & 0.962 \\
& $q_{\mathrm{e}, \mathrm{cal}}(\mathrm{mg} / \mathrm{g})$ & 0.003 & & $q_{\mathrm{e}, \mathrm{cal}}(\mathrm{mg} / \mathrm{g})$ & 0.962 \\
& $K_{1}\left(\mathrm{~min}^{-1}\right)$ & 0.048 & & $K_{2}(\mathrm{~g} /(\mathrm{mg} / \mathrm{min})$ & 41.206 \\
& $R^{2}$ & 0.698 & & $R^{2}$ & 1 \\
& $q_{\mathrm{e}}(\mathrm{mg} / \mathrm{g})$ & 0.071 & & $q_{\mathrm{e}}(\mathrm{mg} / \mathrm{g})$ & 0.071 \\
& $q_{\mathrm{e}, \mathrm{cal}}(\mathrm{mg} / \mathrm{g})$ & 0.110 & & $q_{\mathrm{e}, \mathrm{cal}}(\mathrm{mg} / \mathrm{g})$ & 0.006 \\
& $K_{1}\left(\mathrm{~min}^{-1}\right)$ & 0.082 & & $K_{2}(\mathrm{~g} /(\mathrm{mg} / \mathrm{min}))$ & 2318.144 \\
& $R^{2}$ & 0.915 & & $R^{2}$ & 0.984 \\
\hline
\end{tabular}

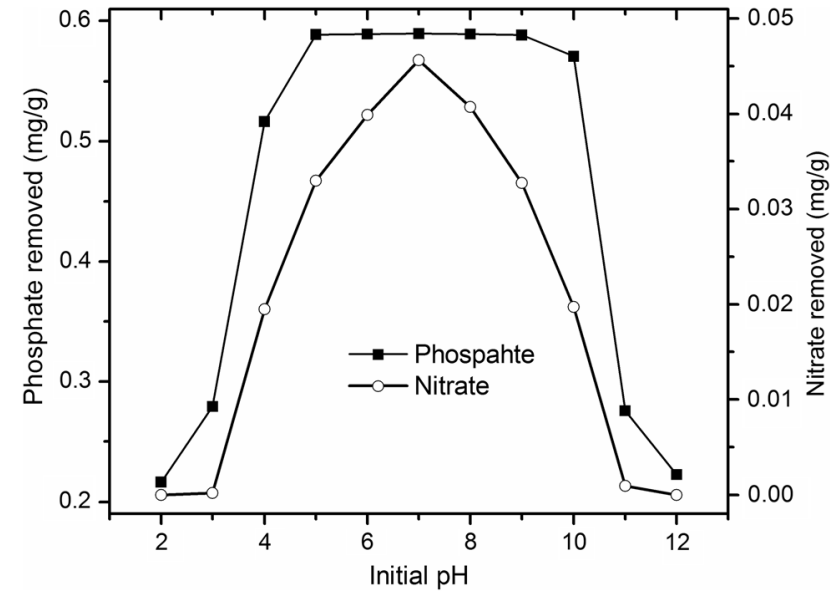

Fig. 2 Effect of $\mathrm{pH}$ on the simultaneous removal of nitrate and phosphate ions

was achieved at $\mathrm{pH} 7\left(0.05 \mathrm{mg} / \mathrm{g} \mathrm{NO}_{3}-\mathrm{N}\right)$. The removal of phosphate in the $\mathrm{pH}$ range mentioned was found to be $0.59 \mathrm{mg} / \mathrm{g}$. The experimental results on the effect of initial solution $\mathrm{pH}$ showed that nitrate removal increased with the increase in $\mathrm{pH}$ from 2 to 7 and declined after $\mathrm{pH} 7$ as shown in Fig. 2. High nitrate removal was achieved at $\mathrm{pH}$ 7 , whereas high phosphate removal was observed in the range of $\mathrm{pH} 5-9$. This could be due to the aqueous phase $\mathrm{pH}$ effect that governs the dissociation of active binding sites on the sorbent (Katal et al. 2012). The decrease in nitrate removal above $\mathrm{pH} 7$ could be due to stronger competition with hydroxide ions, while low removal below pH 7 can be attributed to instability of oxides of SWR at lower $\mathrm{pH}$. This result is similar with the adsorptive removal of nitrate using red mud at $\mathrm{pH} 7$ and lower removal at higher $\mathrm{pH}$ values (Cengeloglu et al. 2006; Katal et al. 2012). On the contrary, high phosphate removal was observed in the $\mathrm{pH}$ range 5-9 and low phosphate removal at $\mathrm{pH}<5$ as shown in Fig. 2. Low phosphate removal at $\mathrm{pH}<5 \mathrm{pH}$ could be due to predominant $\mathrm{H}_{3} \mathrm{PO}_{4}$, which is weakly attached to the sites of the SWR. The low phosphate removal efficiency at higher $\mathrm{pH}$ could be because of the competition of $\mathrm{OH}^{-}$for the adsorption sites with $\mathrm{H}_{2} \mathrm{PO}_{4}{ }^{-}, \mathrm{HPO}_{4}{ }^{2-}$ and $\mathrm{PO}_{4}{ }^{3-}$ (Zhang et al. 2009). Similar result was previously reported (Zhang et al. 2010). In conclusion, the wide $\mathrm{pH}$ range for phosphate removal is of practical importance in the removal of the pollutant.

\section{Effect of adsorbent dose}

The effect of adsorbent dose was studied by varying the dose between 4 and $32 \mathrm{~g} / \mathrm{L}$. It was observed that the percent removal of phosphate ions onto SWR increased from 99.36 to $99.93 \%$ with increasing SWR dose from 4 to $32 \mathrm{~g} / \mathrm{L}$. Similarly, percent removal of nitrate increased from 22.34 to 
$32.20 \%$ with the increased dose of SWR (Fig. 3a, b). It was observed that the amount of phosphate removed increased with increasing SWR dose as shown in Fig. 3a. When the adsorbent dose was increased from 4 to $32 \mathrm{~g} / \mathrm{L}$, the percentage of phosphate adsorption increased from 99.3 to $99.8 \%$. The increase in the percent removal with the increase in the SWR dose was due to the increase in the active binding sites and surface area as dose of the adsorbent increased (Zhang et al. 2010). But, at higher adsorbent dose the uptake of phosphate did not increase significantly probably because saturation could be attained. This result agrees with the previous observation (Özacar 2003). Oppositely, the increase in SWR dose did not cause a significant increase in the removal of nitrate ions. The percent removal increased from 24.3 to $32.2 \%$ when the dose was varied from 4 and $32 \mathrm{~g}$ (Fig. 3b). The little increase in the percentage removal of nitrate with increasing SWR dose is probably because of the absence of any appreciable increase in the effective surface area resulting due to the conglomeration of exchanger particles on SWR surface. This result is similar with the observation of Katal et al. (2012), who observe no appreciable increase in percent removal of nitrate with increasing dose of modified rice husk.

\section{Effect of initial concentration}

The effect of adsorbate concentration on the adsorption was investigated by varying the initial concentration of phosphate between 0.2 and $260 \mathrm{mg} / \mathrm{L}$ and that of nitrate-nitrogen between 3 and $19 \mathrm{mg} / \mathrm{L}$. The results revealed that the percentage removal increased from 70 to $99.97 \%$ with the increase in phosphate concentration from 0.2 to $260 \mathrm{mg} / \mathrm{L}$ (Fig. 4a), while that of nitrate decreased from 26.33 to $6.53 \%$ with the increase in the concentration of nitrate-nitrogen (Fig. 4b). The decrease in nitrate adsorption could suggest lack of available area required for the high initial
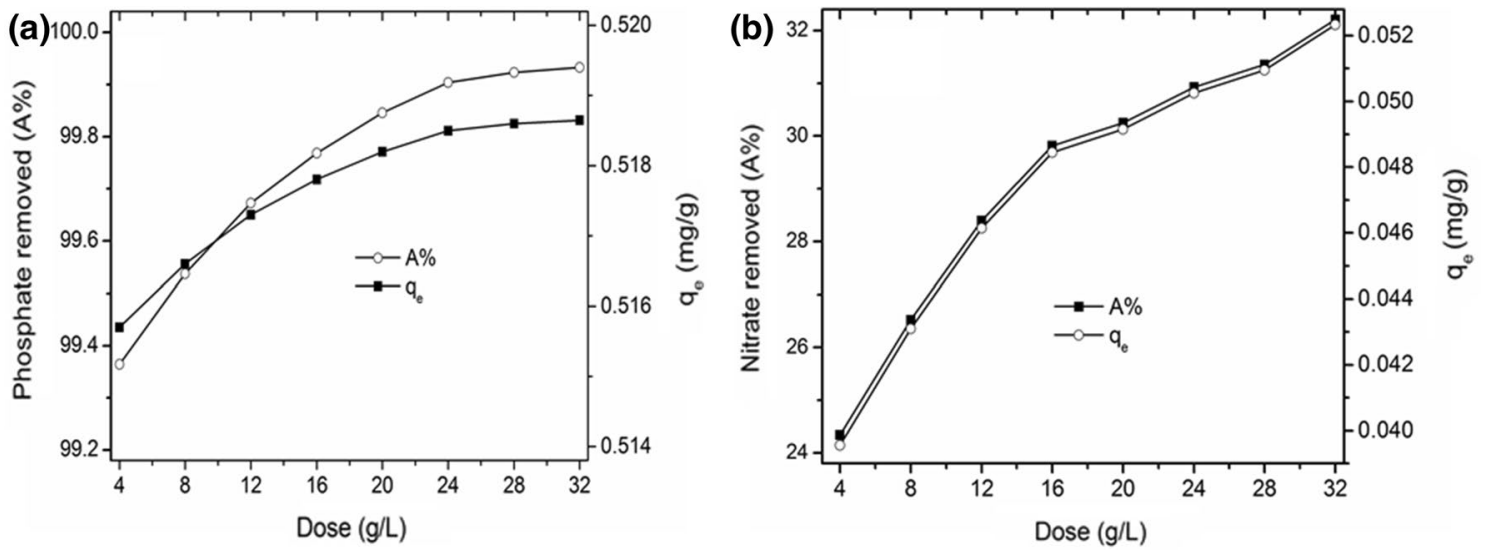

Fig. 3 Effect of adsorbent dose on the simultaneous removal of a phosphate and $\mathbf{b}$ nitrate
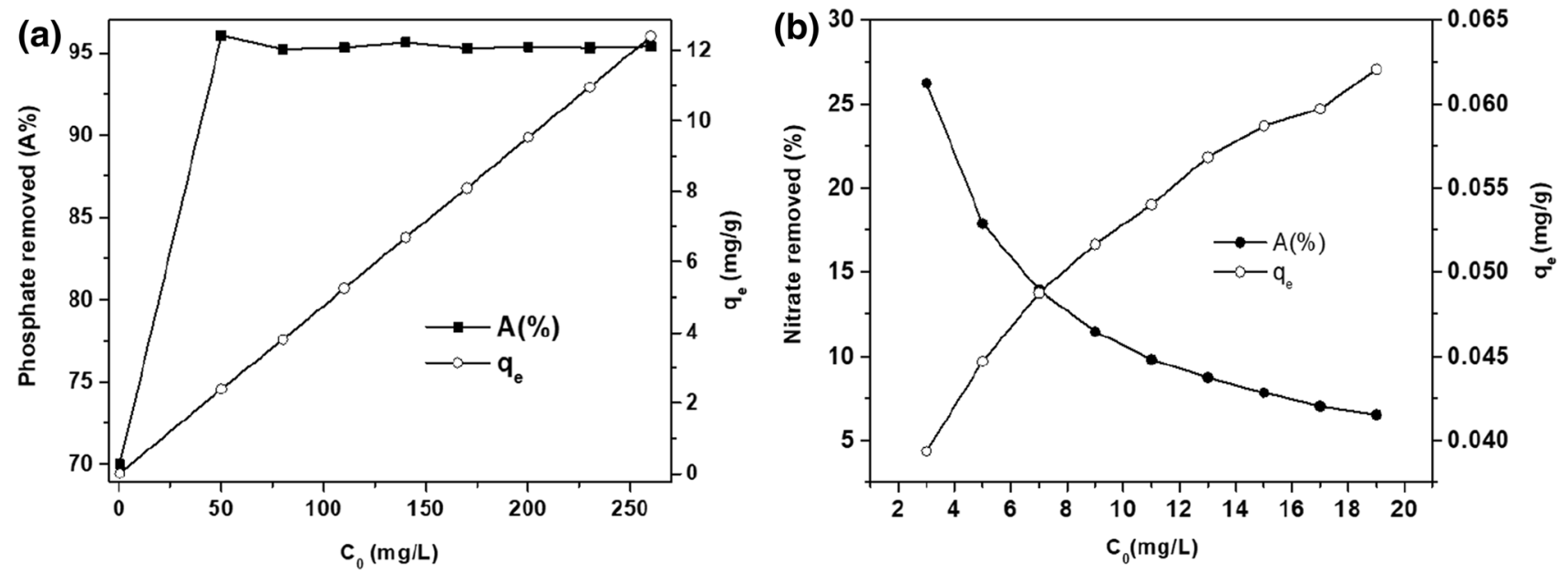

Fig. 4 Effect of initial concentration on the simultaneous removal of a phosphate and $\mathbf{b}$ nitrate 
concentration of nitrate. The higher uptake of nitrate at low concentration may be attributed to the availability of more area on the surface of the adsorbent for lesser number of adsorbate species. This result is similar with the observation made by Katal et al. (2012) where there is a decrease in the percentage removal of nitrate from 94.5 to $46.3 \%$ with the increase in initial concentration from 50 to $300 \mathrm{mg} / \mathrm{L}$. Contrary to this, percentage removal of phosphate ions for the same adsorbent dose showed an increase in the percentage removal from 70 to $95.4 \%$ with increasing concentration of phosphate ions from 0.2 to $260 \mathrm{mg} / \mathrm{L}$ (Fig. 4a). The increase in the percentage removal of phosphate with the increase in the initial concentration could be attributed to the effect of increased concentration gradients between bulk and adsorbent surface resulting in better mass transfer (Milmile et al. 2011).

\section{Adsorption isotherms}

The adsorption isotherm data of simultaneous removal of phosphate and nitrate using SWR were analyzed applying the three commonly used isotherms, Langmuir, Freundlich isotherm and D-R isotherm models, and the summary data are presented in Table 2 . The result showed that adsorption of phosphate and nitrate well described by the Freundlich isotherm with $R^{2}$ values 0.988 and 0.991 , respectively. Likewise, adsorption isotherm data fitted to Langmuir isotherm with $R^{2}$ equal 0.984 for phosphate and 0.955 for nitrate. The fitting of equilibrium adsorption data to Langmuir and
Freundlich isotherm models suggests that both heterogeneous and homogenous adsorption surfaces on the adsorbent involved in the adsorption of the ions. Moreover, examination of $R^{2}$ and RFEP values confirmed that the Freundlich isotherm model better described the equilibrium adsorption with higher $R^{2}$ and smaller RFEP values, giving adsorption capacities of 5.361 and $0.034 \mathrm{mg} / \mathrm{g}$ for phosphate and nitrate, respectively (Table 2). Furthermore, the $R_{\mathrm{L}}$ values found in this study were between 0 and 1 for both adsorbates which depicts the adsorption process to be favorable as presented in Table 2 (Foo and Hameed 2010).

On the other hand, the mean sorption energy was computed according to Eq. (14), where sorption energy less than $8 \mathrm{~kJ} / \mathrm{mol}$ suggests physisorption, while value of mean sorption energy greater than $8 \mathrm{~kJ} / \mathrm{mol}$ indicates chemisorption. The mean sorption energy computed from the D-R equation for phosphate was found to be $8.506 \mathrm{~kJ} / \mathrm{mol}$, while that of nitrate was $3.272 \mathrm{~kJ} / \mathrm{mol}$ (Table 2). The computed mean sorption energy values suggest that physisorption is the main mechanism for the sorptive removal nitrate and chemisorption for phosphate.

\section{Intraparticle diffusion}

Analysis of equilibrium data using intraparticle diffusion model shows that intraparticle diffusion is not the rate-determining step as the graph of $q_{\mathrm{t}}$ versus $t^{0.5}$ did not pass through the origin as shown in Fig. 5a, b. The plots the adsorption of phosphate and nitrate were not linear throughout the whole

Table 2 Isotherm parameters for the removal of nitrate ions by untreated SWR

\begin{tabular}{|c|c|c|c|c|}
\hline & \multicolumn{2}{|c|}{ Freundlich isotherm } & \multicolumn{2}{|c|}{ Langmuir isotherm } \\
\hline & Parameters & Value & Parameters & Value \\
\hline \multirow[t]{5}{*}{ Phosphate } & $k_{\mathrm{f}}(\mathrm{mg} / \mathrm{g})$ & 5.361 & $q_{\max (\mathrm{mg} / \mathrm{g})}$ & 13.150 \\
\hline & $N$ & 2.727 & $b(\mathrm{~L} / \mathrm{mg})$ & 0.367 \\
\hline & $R^{2}$ & 0.988 & $R^{2}$ & 0.984 \\
\hline & RFEP & 1.619 & $R_{\mathrm{L}}$ & $0.010-0.932$ \\
\hline & & & RFEP & 2.199 \\
\hline \multirow[t]{12}{*}{ Nitrate } & $k_{\mathrm{f}}(\mathrm{mg} / \mathrm{g})$ & 0.034 & $q_{\max (\mathrm{mg} / \mathrm{g})}$ & 0.065 \\
\hline & $N$ & 4.740 & $b(\mathrm{~L} / \mathrm{mg})$ & 0.594 \\
\hline & $R^{2}$ & 0.991 & $R^{2}$ & 0.955 \\
\hline & RFEP & $3.825 \mathrm{E}-6$ & $R_{\mathrm{L}}$ & $0.081-0.359$ \\
\hline & & & RFEP & $1.931 \mathrm{E}-5$ \\
\hline & \multicolumn{2}{|l|}{ D-R isotherm } & \multicolumn{2}{|l|}{$\mathrm{D}-\mathrm{R}$ isotherm } \\
\hline & \multicolumn{2}{|l|}{ Phosphate } & \multicolumn{2}{|l|}{ Nitrate } \\
\hline & $q_{\mathrm{m}}$ & $5.474 \mathrm{E}-4$ & $q_{\mathrm{m}}$ & $2.150 \mathrm{E}-6$ \\
\hline & $\beta\left(\mathrm{mol}^{2} / \mathrm{kJ}^{2}\right)$ & 0.00691 & $\beta\left(\mathrm{mol}^{2} / \mathrm{kJ}^{2}\right)$ & 0.0467 \\
\hline & $R^{2}$ & 0.996 & $R^{2}$ & 0.992 \\
\hline & $E_{\mathrm{D}-\mathrm{R}}(\mathrm{kJ} / \mathrm{mol})$ & 8.506 & $E_{\mathrm{D}-\mathrm{R}}(\mathrm{kJ} / \mathrm{mol})$ & 3.272 \\
\hline & RFEP & $6.128 \mathrm{E}-11$ & RFEP & $8.659 \mathrm{E}-16$ \\
\hline
\end{tabular}



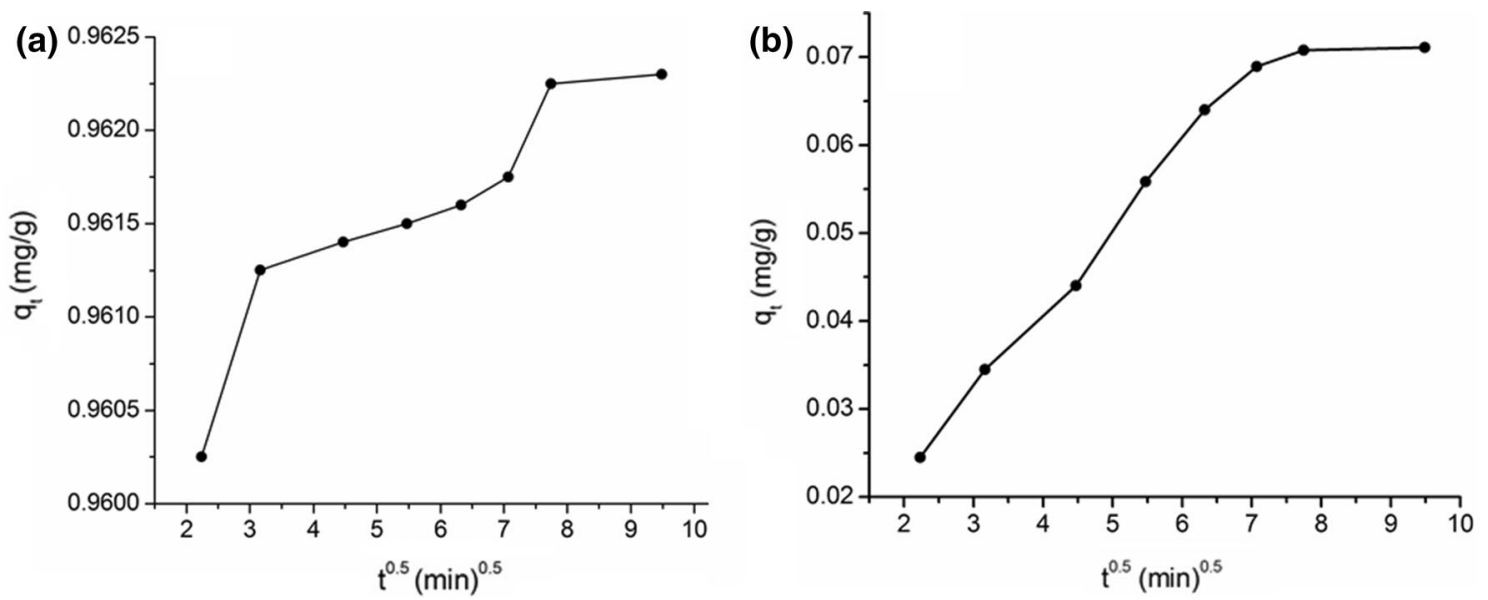

Fig. 5 Intraparticle diffusion plot of simultaneous removal of $\mathbf{a}$ phosphate and $\mathbf{b}$ nitrate ions

range of time and do not pass through the origin (Fig. 5). This indicates that intraparticle diffusion was not the only rate-limiting step in the simultaneous adsorption of nitrate and phosphate. Therefore, other mass transfer processes like film diffusion and bulk diffusion could be there in determining the mass transfer mechanism of nitrate and phosphate ions from the bulk solution to the adsorbent surface.

\section{Effect of coexisting ions}

The effect of common coexisting ions, such as chloride, sulfate and bicarbonate, in wastewater on the simultaneous adsorption of phosphate and nitrate was investigated by varying the concentration of the anions from 5 to $100 \mathrm{mg} / \mathrm{L}$ in the solution. The result shows that the presence of individual or the mixture of the three ions in the solution did not significantly affect the removal efficiency of phosphate when compared with the removal efficiency of phosphate without the presence of the ions in the solution (Fig. 6a). The removal efficiency of phosphate without the presence of the ions was represented by "control" in Fig. 6a. On the hand, the increase in concentration of all the coexisting ions significantly affected the removal efficiency. The effect of chloride is not as prominent as bicarbonate and sulfate indicated in Fig. 6b. The result reveals that percent removal of nitrate ion by SWR significantly decreased with increasing the concentration from 5 to $100 \mathrm{mg} / \mathrm{L}$ of the coexisting anions (Fig. 6b). The decrease in percent removal of nitrate ion with the increase in the concentration of the coexisting ions could be due to the non-specificity of the adsorbent sites for nitrate adsorption or lack of available surface area on SWR for high concentration of the anions. Nitrate removal significantly decreased with the increase in bicarbonate concentration from 5 to $100 \mathrm{mg} / \mathrm{L}$ because the increase in concentration of bicarbonate is expected to raise the solution $\mathrm{pH}$ above the optimum $\mathrm{pH}$, while decreased nitrate removal
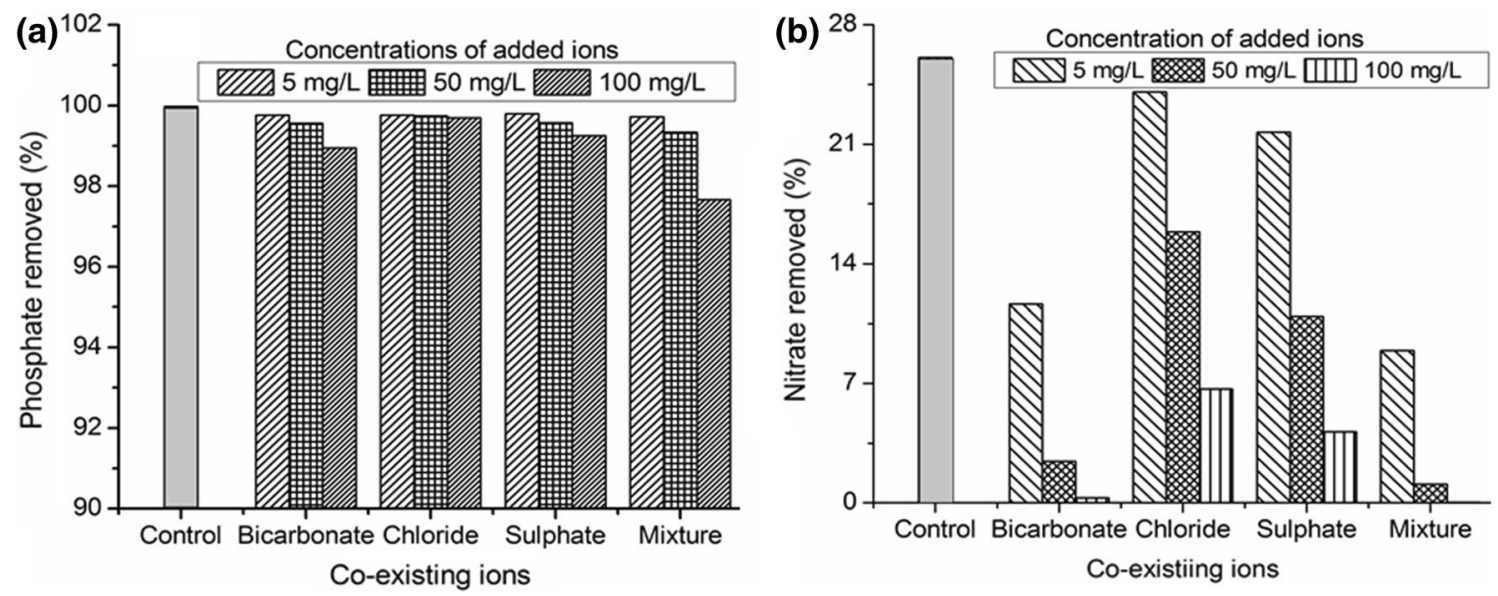

Fig. 6 Effect of coexisting ions on the simultaneous removal of a phosphate and $\mathbf{b}$ nitrate 


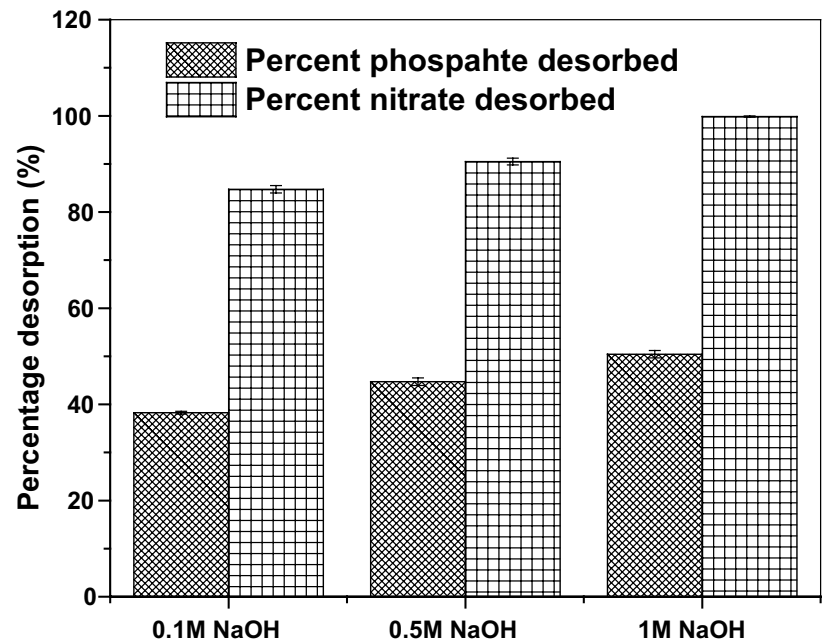

Fig. 7 Simultaneous desorption of phosphate and nitrate using $\mathrm{NaOH}$ solution

with the increase in sulfate concentration could be due to high charge density of sulfate as compared to nitrate as previously described (Katal et al. 2012). Besides, sulfate ion can form both inner- and outer-sphere complexes as opposed to nitrate which only forms outer-sphere complex and is a weak binding anion. The effect of coexisting anions can be summarized in the decreasing order of their effect on nitrate removal as: bicarbonate $>$ sulfate $\gg$ chloride. The result of the effect of the coexisting anions on the nitrate removal by SWR is similar with the previous observation made by Katal et al. (2012).

\section{Desorption}

The experimental results of the effect of $\mathrm{pH}$ revealed that the adsorption of phosphate and nitrate significantly decreased in the extreme $\mathrm{pH}$ values ("Effect of solution $\mathrm{pH}$ " section). This could suggest that desorption of the adsorbates can be effective using either extreme acidic or basic $\mathrm{pH}$. The data found from the desorption experiment showed nearly $50 \%$ of the adsorbed phosphate were desorbed by $1.0 \mathrm{M} \mathrm{NaOH}$. Unlike phosphate $100 \%$, desorption of nitrate was observed using $1 \mathrm{M} \mathrm{NaOH}$. The results of desorption experiments are given in Fig. 7. This result agrees with the observations of previous researchers (Dai et al. 2011; Zhang et al. 2009, 2010). Moreover, when concentration of $\mathrm{NaOH}$ increased in similar manner, the nitrate percent desorption increased from 84.18 to $99.75 \%$ (Fig. 7) and similar result was presented by Schick et al. (2011) where $0.1 \mathrm{M} \mathrm{NaOH}$ desorbed $85 \%$ nitrate from the spent modified rice husk. The nearly complete desorption of nitrate could suggest nitrate ions are weakly bound to the SWR.

\section{Removal of phosphate and nitrate from wastewater}

Adsorption experiment conducted using real wastewater showed that phosphate removal decreased to $77.5 \%$ for initial phosphate concentration of $7.17 \mathrm{mg} / \mathrm{L}$, while that of nitrate decreased to $4.6 \%$ for initial nitrate-nitrogen concentration $1.3 \mathrm{mg} / \mathrm{L}$. These significant decreases in phosphate removal could be due to the organic content and high electrical conductivity that might have halted the adsorption process via blocking and competition for the adsorbent sites, respectively.

\section{Conclusions}

This work dealt with simultaneous phosphate and nitrate removal using untreated solid water residue collected from alum and sulfuric acid factory. The result showed phosphate and nitrate adsorption on SWR was dependent on solution $\mathrm{pH}$. The adsorbent showed low tendency toward adsorbing nitrate $(0.071 \mathrm{mg} / \mathrm{g})$, while the affinity of the SWR toward phosphate $(0.962 \mathrm{mg} / \mathrm{g})$ was good within equilibrium time. Higher affinity of the SWR to phosphate was further confirmed by desorption experiment whereby nearly $100 \%$ nitrate and 50\% phosphate were desorbed with $1 \mathrm{M} \mathrm{NaOH}$. Further analysis showed mean sorption energy of $8.506 \mathrm{~kJ} /$ mole which justified the interaction between phosphate and SWR was predominantly chemical adsorption. Oppositely, the removal mechanism for nitrate was predominantly physical adsorption with mean sorption energy equal to $3.272 \mathrm{~kJ} /$ mole. Study on application of the SWR for real wastewater treatment showed promising result in terms of removing phosphate removal though efficiency was decreased, but showed very low tendency for nitrate. Finally, SWR has the potential to extract phosphate from wastewater and phosphate-loaded SWR could be used as a soil conditioner with further investigation.

Acknowledgements The authors would like to thank School of Graduate Studies of Jimma University for financial support and Awash Melkassa Aluminium Sulphate and Sulfuric Acid Factory for their cooperation during adsorbent media collection.

Open Access This article is distributed under the terms of the Creative Commons Attribution 4.0 International License (http://creativecommons.org/licenses/by/4.0/), which permits unrestricted use, distribution, and reproduction in any medium, provided you give appropriate credit to the original author(s) and the source, provide a link to the Creative Commons license, and indicate if changes were made. 


\section{References}

Association APH, Association AWW (1989) Standard methods for the examination of water and wastewater. American Public Health Association, New York

Baraka A, El-Tayieb MM, Shafai ME, Mohamed NY (2012) Sorptive removal of phosphate from wastewater using activated red mud. Aust J Basic Appl Sci 6:500-510

Boparai HK, Joseph M, O'Carroll DM (2011) Kinetics and thermodynamics of cadmium ion removal by adsorption onto nano zerovalent iron particles. J Hazard Mater 186:458-465

Cengeloglu Y, Tor A, Ersoz M, Arslan G (2006) Removal of nitrate from aqueous solution by using red mud. Sep Purif Technol $51: 374-378$

Chiu S-Y, Kao C-Y, Chen T-Y, Chang Y-B, Kuo C-M, Lin C-S (2015) Cultivation of microalgal Chlorella for biomass and lipid production using wastewater as nutrient resource. Bioresour Technol 184:179-189

Dai J, Yang H, Yan H, Shangguan Y, Zheng Q, Cheng R (2011) Phosphate adsorption from aqueous solutions by disused adsorbents: chitosan hydrogel beads after the removal of copper (II). Chem Eng J 166:970-977

Fekadu F (2016) Experimental evaluation of activated termite mound for fluoride adsorption. IOSR J Environ Sci Toxicol Food Technol 10:119-132

Fink JR, Inda AV, Bavaresco J, Barrón V, Torrent J, Bayer C (2016) Adsorption and desorption of phosphorus in subtropical soils as affected by management system and mineralogy. Soil Tillage Res 155:62-68

Foo KY, Hameed BH (2010) Insights into the modeling of adsorption isotherm systems. Chem Eng J 156:2-10

Galloway JN, Cowling EB (2002) Reactive nitrogen and the world: 200 years of change. AMBIO J Hum Environ 31:64-71

Guedes P, Mateus EP, Almeida J, Ferreira AR, Couto N, Ribeiro AB (2016) Electrodialytic treatment of sewage sludge: current intensity influence on phosphorus recovery and organic contaminants removal. Chem Eng J 306:1058-1066

Habte H, Zewge F, Redi M (2014) Removal of azo dye from water by absorption using waste residue from alum manufacturing process. Afr J Environ Sci Technol 8:482-490

Han DS, Batchelor B, Park SH, Abdel-Wahab A (2012) As (V) adsorption onto nanoporous titania adsorbents (NTAs): effects of solution composition. J Hazard Mater 229:273-281

Ho Y-S, McKay G (1999) Pseudo-second order model for sorption processes. Process Biochem 34:451-465

Huang H, Liu J, Zhang P, Zhang D, Gao F (2017) Investigation on the simultaneous removal of fluoride, ammonia nitrogen and phosphate from semiconductor wastewater using chemical precipitation. Chem Eng J 307:696-706

Kamiyango M, Masamba W, Sajidu S, Fabiano E (2009) Phosphate removal from aqueous solutions using kaolinite obtained from Linthipe, Malawi. Phys Chem Earth Parts A/B/C 34:850-856

Katal R, Baei MS, Rahmati HT, Esfandian H (2012) Kinetic, isotherm and thermodynamic study of nitrate adsorption from aqueous solution using modified rice husk. J Ind Eng Chem 18:295-302

Kebede B, Beyene A, Fufa F, Megersa M, Behm M (2016) Experimental evaluation of sorptive removal of fluoride from drinking water using iron ore. Appl Water Sci 6:57-65

Khelifi O, Kozuki Y, Murakami H, Kurata K, Nishioka M (2002) Nutrients adsorption from seawater by new porous carrier made from zeolitized fly ash and slag. Mar Pollut Bull 45:311-315

Kooh MRR, Dahri MK, Lim LB (2017) Removal of the methyl violet 2B dye from aqueous solution using sustainable adsorbent Artocarpus odoratissimus stem axis. Appl Water Sci 7:3573-3581
Lagergren S (1898) About the theory of so-called adsorption of soluble substances. Sven Vetenskapsakad Handingarl 24:1-39

Langmuir I (1918) The adsorption of gases on plane surfaces of glass, mica and platinum. J Am Chem Soc 40:1361-1403

Liang Q (2007) Simultaneous phosphorus and nitrogen removal using aluminum based water treatment residual. Colorado State University. Libraries

Luo W, Phan HV, Xie M, Hai FI, Price WE, Elimelech M, Nghiem LD (2017) Osmotic versus conventional membrane bioreactors integrated with reverse osmosis for water reuse: biological stability, membrane fouling, and contaminant removal. Water Res 109:122-134

Milmile SN, Pande JV, Karmakar S, Bansiwal A, Chakrabarti T, Biniwale RB (2011) Equilibrium isotherm and kinetic modeling of the adsorption of nitrates by anion exchange Indion NSSR resin. Desalination 276:38-44

Olgun A, Atar N, Wang S (2013) Batch and column studies of phosphate and nitrate adsorption on waste solids containing boron impurity. Chem Eng J 222:108-119

Özacar M (2003) Adsorption of phosphate from aqueous solution onto alunite. Chemosphere 51:321-327

Painting S et al (2007) Assessing the impact of nutrient enrichment in estuaries: susceptibility to eutrophication. Mar Pollut Bull 55:74-90

Schick J, Caullet P, Paillaud J-L, Patarin J, Mangold-Callarec C (2011) Nitrate sorption from water on a Surfactant-Modified Zeolite. Fixed-bed column experiments. Microporous Mesoporous Mater 142:549-556

Song X, Pan Y, Wu Q, Cheng Z, Ma W (2011) Phosphate removal from aqueous solutions by adsorption using ferric sludge. Desalination 280:384-390

Tiemeyer B, Kahle P, Lennartz B (2009) Phosphorus losses from an artificially drained rural lowland catchment in North-Eastern Germany. Agric Water Manag 96:677-690

Vitousek PM, Hättenschwiler S, Olander L, Allison S (2002) Nitrogen and nature. AMBIO J Hum Environ 31:97-101

Weber WJ, Morris JC (1963) Kinetics of adsorption on carbon from solution. J Sanit Eng Div 89:31-60

Wei X, Viadero RC Jr, Bhojappa S (2008) Phosphorus removal by acid mine drainage sludge from secondary effluents of municipal wastewater treatment plants. Water Res 42:3275-3284

$\mathrm{Wu} \mathrm{H}$ et al (2015) A review on the sustainability of constructed wetlands for wastewater treatment: design and operation. Bioresour Technol 175:594-601

Zeng L, Li X, Liu J (2004) Adsorptive removal of phosphate from aqueous solutions using iron oxide tailings. Water Res 38:1318-1326

Zhang G, Liu H, Liu R, Qu J (2009) Removal of phosphate from water by a $\mathrm{Fe}-\mathrm{Mn}$ binary oxide adsorbent. J Colloid Interface Sci 335:168-174

Zhang J, Shen Z, Shan W, Chen Z, Mei Z, Lei Y, Wang W (2010) Adsorption behavior of phosphate on Lanthanum(III) doped mesoporous silicates material. J Environ Sci 22:507-511

Zhao Y, Wang J, Luan Z, Peng X, Liang Z, Shi L (2009) Removal of phosphate from aqueous solution by red mud using a factorial design. J Hazard Mater 165:1193-1199

Publisher's Note Springer Nature remains neutral with regard to jurisdictional claims in published maps and institutional affiliations. 